Reclaiming bodily dispositions through the humanities: Homeless people learning

John Stevenson (Griffith University)

Irena Yashin-Shaw (Griffith University)

Peter Howard (Australian Catholic University) 


\title{
Reclaiming bodily dispositions through the humanities: Homeless people learning Abstract
}

\begin{abstract}
This paper examines data drawn from interviews with homeless people who were undertaking a Clemente programme (Shorris, 2000) offered by the Australian Catholic University in the Vincentian Village in East Sydney (Yashin-Shaw, Howard \& Butcher, 2005). The Clemente programme is based on the belief that an education in the humanities empowers people to engage in a more controlled way with the world in which they live, and that they will therefore be less likely to react simply to contexts and events. Two of the striking things about the interview data were the rejection of 'vocational courses' and the way in which the learners referred to changes in their bodies that flowed from the humanities programme: the way they walked, the straightness of their backs, together with the metaphor of climbing. The present paper seeks to interpret these and other changes in terms of Mauss' (1934) and Bourdieu's (1971) conceptions of habitus, bodily hexis and dispositions, and possible implications for teaching and learning in vocational education.
\end{abstract}

\section{Introduction}

An education program, for homeless people, called Clemente was initiated by the Australian Catholic University in the Vincentian Village in East Sydney during 2003-2004 (Yashin-Shaw, Howard \& Butcher, 2005). The Clemente program was conceptualised by Shorris (2000) on the premise that education in the humanities would help move socially disenfranchised people out of the cycle of poverty and homelessness. The program is therefore different from 'life skills' or 'vocational' courses. It does not seek to train people directly for specific kinds of work, because work on its own is not seen as the "structural solution to poverty, particularly multigenerational poverty" (Shorris 2000, p.63). Rather it is premised on the belief that studying the humanities through courses such as philosophy and ethics serves to engage and empower people to think about and reflect on the world in which they live, so that they might become less likely to react simply to contexts and events and more likely to examine, question and contemplate. In doing so, learners would engage in "activity with other people at every level" (Shorris 2000, p.127) and become engaged 'public' citizens.

In Australia, the Clemente program is a collaborative higher education initiative of ACU National and community agencies that enhances students' learning about themselves as worthwhile human beings and restores their capacity to live as individuals within the Australian community. It is distinctive in its transformational learning approaches with marginalised Australians, re-engaging them with their community through the study of the Humanities. A key belief underlying the Clemente program is attributed to Socrates in the apology: that "the unexamined life is not worth living”. In positive terms, the Clemente program holds that the examined life can prove to be worth living. As such, Clemente stands in contrast to the forms of education traditionally offered to marginalised people.

This present paper seeks to interpret the self-reported changes that occurred during the program in terms of Bourdieu's $(1990,1991)$ conceptions of habitus, bodily hexis and dispositions.

Bodily hexis is political mythology realized, em-bodied, turned into a permanent disposition, a durable way of standing, speaking, walking, and thereby of feeling and thinking. (Bourdieu, 1990, pp. 69-70),

That is, the paper is not situated in the literatures on lifelong learning (Sutherland \& Crowther, 2006), critical theory (e.g. Habermas, 1978), or empowerment (e.g. Freire, 1995). Rather the paper seeks to examine 'embodied knowledge', not in terms of mental schemas, but in terms of Bourdieu's idea that individuals act in the present in a way that is mediated by dispositions; that these dispositions are not known in terms of mental schemas or language; and that these dispositions are reflected in such physical characteristics as how an individual stands, walks. 
apparently insignificant aspects of things, situations and practices of everyday life. Thus the modalities of practices, the ways of looking, sitting, standing, keeping silent, or even of speaking ('reproachful looks' or 'tones', 'disapproving glances' and so on) are full of injunctions that are powerful and hard to resist precisely because they are silent and insidious, insistent and insinuating. (It is this secret code which is explicitly denounced in the crises characteristic of the domestic unit, such as marital or teenage crises: the apparent disproportion between the violence of the revolt and the causes which provoke it stems from the fact that the most anodyne actions or words are now seen for what they are - as injunctions, intimidations, warnings, threats - and denounced as such, all the more violently because they continue to act below the level of consciousness and beneath the very revolt which they provoke (Bourdieu, 1991, p. 51)

\section{Homelessness}

A homeless person is defined as someone who does not have access to permanent safe, secure and adequate housing. Chamberlain and MacKenzie (2001) have identified three levels of homelessness. Primary homelessness which includes people without conventional accommodation, such as people living on the streets, sleeping in parks, squatting in derelict buildings or using cars or railway carriages for temporary shelter; Secondary homelessness which includes people who move frequently from one form of temporary shelter to another; people residing temporarily with other households or people staying in boarding houses on a short term basis; and Tertiary homelessness which refers to people who live in boarding houses on a medium to long term basis (13 weeks or longer) or who have accommodation and are in the process of moving out of homeless but still maintain a 'homeless' mentality in the sense that they are not as yet engaged in the social and economic life of their community. For the purposes of this project, all three levels were included in the term 'homeless'. People in such circumstances are among the most marginalised people in Australia and are in danger of becoming disengaged and alienated from mainstream society, slipping into a culture of dependence, poverty and social exclusion.

\section{The Program}

The Clemente program assumes that social isolation and the disadvantage that stems from that can, to some extent, be addressed through education that helps people to understand the inherent benefits of engaged citizenship (Shorris 2000; Butcher, Howard and McFadden 2003). Unfortunately such an education is often inaccessible to the very people who would benefit most. Homeless people simply do not consider taking tertiary courses in moral philosophy or literature. Moreover, society socialises them into believing that the main problem is that they have deficits in vocational skills and need re-training in such skills in order to enter the workforce. 
Because of the circumstances of homeless people, the Clemente program advocates that university level humanities courses with appropriately qualified lecturers be taught in a community setting. The following courses were made available: Ethics: Living an examined life; A History of Modern Australia; and Spirituality. They were taught on site in the community setting of Vincentian Village by staff from Australian Catholic University. Participants were supported between lectures with a one-on-one volunteer learning partner, recruited from the corporate, business and government sectors; and also, where necessary, by welfare staff at the Village. It was expected that there would be substantial associated benefits in delivering the course in this way e.g. participants forming supportive relationships among themselves and with others (such as lecturers and learning partners); achieving personal responsibility; experiencing success and changing perceptions. MacKnee and Mervyn (2002) have identified such factors as being critical in facilitating the transition off the streets.

A number of studies have shown that education can lead to improvements in self-confidence (Carlton \& Soulsby, 1999), self-efficacy (Wertheimer, 1997), self-understanding (Cox \& Ascall, 1994), a sense of belonging to a social group (Emler \& Fraser, 1999) as well as competencies, communication skills and civic engagement (Emler \& Fraser, 1999). Hammond (2004) linked these benefits to long-term health outcomes and concluded that education "can lead to improved wellbeing, increased efficacy, protection and recovery from mental health difficulties, and more effective coping, including coping with physical ill health” (p. 553). The Clemente program has enabled marginalised people to experience:

- access to independent, active, adult learning;

- opportunity to question and consider their society, its development, their place in it and possible contributions to it;

- opportunity to reflect upon spiritual, moral and ethical questions and on their own experience of life; and,

- rigorous scholarly study and practice of visual, dramatic and literary arts.

\section{Theoretical Considerations}

In this paper, the program and its outcomes are considered in terms of Bourdieu's $(1990,1991)$ concepts of habitus and bodily hexis. The idea of habitus is used extensively by Bourdieu (1990, 1991) and previously by Mauss (1934) to refer to enduring socialised embodied thoughts, perceptions and actions.

Mauss (1934, p. 73) introduces the concept of habitus as follows:

Hence I have had this notion of the social nature of the 'habitus' for many years. Please note that I use the Latin word - it should be understood in France - habitus. The word translates infinitely better than 'habitude' (habit or custom), the 'exis', the 'acquired ability' and 'faculty' of Aristotle (who was a psychologist). It does not designate those metaphysical habitudes, that mysterious 'memory', the subjects of volumes or short and famous theses. These 'habits' do not just vary with individuals and their limitations, they vary especially between societies, educations, proprieties and fashions, prestiges. In them we should see the techniques of collective and practical reason rather than, in the ordinary way, merely the soul and its repetitive faculties.

According to Bourdieu (1990, p. 53):

The conditionings associated with a particular class of conditions of existence produce habitus, systems of durable, transposable dispositions, structured structures predisposed to function as structuring structures, that is, as principles which generate and organize practices and representations that can be objectively adapted to their outcomes without presupposing a conscious aiming at ends or an express mastery of the operations necessary in order to attain them

For Bourdieu, these dispositions are not necessarily verbalisable, and do not exist as mental representations; however they do operate as schemes so that they bring past experiences into 
understanding and dealing with present circumstances. That is the habitus 'a product of history, produces individual and collective practices - more history - in accordance with schemes generated by history' (p. 54). It is 'embodied history, internalized as a second nature and so forgotten as history - (it) is the active presence of the whole past of which it is the product' (p. 56).

For Bourdieu:

The body believes in what it plays at: It weeps if it mimes grief. It does not represent what it performs, it does not memorize the past, it enacts the past, bringing it back to life. What is 'learned by the body' is not what one has, like knowledge that can be brandished, but something that one is... As Havelock (1963), from whom this argument is borrowed, points out, the body is constantly mingled with all the knowledge it reproduces, and this knowledge never has the objectivity it derives from objectification in writing and the consequent freedom with respect to the body. (Bourdieu, 1990, p. 73)

One of the ways in which the habitus persists is through the way it 'tends to favour experiences likely to reinforce it' (p. 60). It 'tends to protect itself from crises and critical challenges by providing itself with a milieu to which it is as pre-adapted as possible' (p. 60).

Because the habitus is a product of repeated encounters with a field of activity (which itself has been shaped by collective habitus), and because it is embodied, it is durable and hard to shift. So, changing the habitus is a challenge.

Thus the modalities of practices, the ways of looking, sitting, standing, keeping silent, or even of speaking ('reproachful looks' or 'tones', 'disapproving glances' and so on) are full of injunctions that are powerful and hard to resist precisely because they are silent and insidious, insistent and insinuating. (p. 51)

The power of suggestion which is exerted through things and persons and which, instead of telling the child what he must do, tells him what he is, and thus leads him to become durably what he has to be, is the condition for the effectiveness of all kinds of symbolic power that will subsequently be able to operate on a habitus predisposed to respond to them. (p. 52)

One problem in using Bourdieu's concept of habitus is that a literal reading would suggest that substantial change in habitus would require being re-born and re-socialised from birth. With such a fully deterministic reading of Bourdieu, there would be no point in the Clemente project as such a fundamental change is not possible for homeless people undertaking a few university courses. The more modest aim of the Clemente program is to move the participants away from reacting simply to contexts and events, i.e. seeking to interrupt the direct operation of the habitus, their automatic 'schemes', challenging the participants to resist their history-based anticipations about the results of present actions. Presumably, over time, such repeated experiences of critical thinking would lead to some changes in the schemes themselves, as new personal histories become embodied.

Adopting Bourdieu's concepts in trying to bring about such personal change, then, the Clemente program might be thought about as trying to deal with the factors that have reinforced the formation of the habitus and its continually reinforced operation in pre-determining individual and collective actions. Thus, the intervention might be seen as trying to increase participants' awareness of their habitus: their own and others' dispositions and their relationship with such different social fields as those of work; and helping them to get some critical distance from the direct automatic operation of their own dispositions.

\section{Method}

(a) The Clemente Courses

Participants for the initial Clemente course, which took place in Semester 2 of 2003, were recruited from Vincentian Villiage as well as other welfare organisations such as Edward Eager Lodge, Matthew Talbot Hostel and Mission Australia. This was done through the dissemination of flyers, which staff at Vincentian Village distributed and also placed in visible locations around the 
agencies e.g. the 'soup kitchen'. Respondents wishing to enrol in the course were interviewed to determine eligibility. The two criteria for enrolment were, firstly the ability to read (to the level of reading a newspaper) and write (a short paragraph) and, secondly, a preparedness to make a commitment to the course through attending lectures and tutorials and undertaking assignments. All fifteen people who applied were accepted. The first course, called Ethics: Living an examined life, commenced on the nineteenth of September 2003. Eight of those commencing the course completed at the end of 2003.

The second unit in the Clemente Program offered at Vincentian Village in Semester 1 of 2004 was Australian History. The eight students who completed the first course continued into the second one. As well, seven additional students were recruited via the means described above. Fourteen of the 15 participants completed Semester 12004.

\section{(b) The Interviews and Focus Groups}

An emerging research methodology focussing upon the values of human dignity and respect for the individual together with the underlying research principles of mutual benefit and reciprocity formed the basis of the development and implementation of the interview process and the feedback of the resultant outcomes to the participants and community agencies. Voluntary participants for the research were drawn from the Clemente program participants. Of the fifteen people in the program at the time of the data gathering, nine agreed to be interviewed. Interviews were undertaken by a research assistant from another university, not involved in the delivery of the program. She interviewed both individually and in small groups, using a combination of structured and unstructured approaches. The approach was influenced by a number of considerations such as participants needing to be gently pressed into actively reflecting on the attitudinal changes they may have been experiencing as a result of undertaking the program; and participants needing some scaffolding or assistance in verbalising responses to encourage exploration of changes in their attitudes and notions of self efficacy.

The interviews were intended to be responsive to individual contexts and experiences. Too structured an approach was likely to "inhibit the free expression of feeling or the expression of unanticipated responses" (Qureshi, 1992). While the core of the interview covered a number of predetermined questions, there was also opportunity for more open-ended discussion. The interviewer tried to identify and follow up issues that arose during the course of the interview, which, with some assisted unpacking, yielded useful information.

Focus group discussions were also undertaken in order to complement data obtained from the interview, as focus groups have a different dynamic to a one-on-one interview, and therefore have the potential to generate different sorts of data arising from the 'give and take' of group discussion.

(c) The Analyses

The interviews and discussions were audio taped and transcribed. The transcriptions were analysed in terms of statements about three aspects of the program: inputs, processes and outcomes (Stufflebeam, 1983), which, for the investigation of this program, can be depicted as follows: 
Outcomes: Reported outcomes and changes, attributed to the program

Learning Processes: Reported ways in which the learning and changes occurred during the program

Teaching Approaches: Reports about the nature of the course processes

\section{Findings \\ Outcomes}

Extracts from the transcripts reporting outcomes and changes are given in Figure 1. The changes were reported by participants in such conventional terms of skills, engagement, renewed direction, interest, feeling responsible, confidence, thinking abilities and words denoting critical analysis. Interestingly, some of the participants also referred to concurrent bodily changes: straightness of back, walking attitude, deportment, kinesis (Kerry), walking with purpose (Tess), and climbing (Lindsay, Tess). The program appeared to be breathing new life into the participants and this was evident to some of them as bodily changes.

\section{[FIGURE 1 ABOUT HERE]}

\section{Learning Processes}

As depicted in Figure 2, the extracts indicate that aspects of the learning processes valued by the participants included listening, accessing, relating to life, seeing others' views and 'elements', being open, healthy debate, bringing ideas out, writing, talking, expressing optimally, quality thinking, applying, concluding, the engendering of renewed purposefulness, structuring, valuing time, and reconnecting with and having a stake in society.

Again there were the metaphors of walking (David), giving out energy or body language (David), loss of physical pain (David), and reaching and touching (Sarah).

\section{[FIGURE 2 ABOUT HERE]}

\section{Teaching Approaches}

From Figure 3, as one would expect in an adult learning setting, the extracts from the transcripts show that the aspects of the teaching approaches that were valued by participants were: Flexibility, interactivity, positive atmosphere, honesty, unbiased presentation, focus, timelines, ensuring understanding, opening the door, connecting with learners' realities, structure and discipline, comprehensive resources, credible accreditation, interesting, safe, demanding, self-motivating, treated as an adult, inclusion, engagement, confronting.

\section{[FIGURE 3 ABOUT HERE]}

\section{Discussion}

Bourdieu (1990) warns the researcher about imposing unchallenged objectifications on research data taken from practice. He would apply this injunction even to the use of the concept of habitus. Rather he advocates suspending pre-determined ways of interpreting data and seeking to see the data in the ways in which they are meaningful in practice - trying to check the objectifications and the subjective data against each other so that the world as it is experienced in practice becomes the driving way of forming justified and coherent understandings of phenomena. 
the position of the 'objective' observer who, seeking to interpret practices, tends to bring into the object the principles of his relation to the object, as is shown for example by the privileged status he gives to communicative and epistemic functions which inclines him to reduce exchanges to purely symbolic exchanges... This critical reflection on the limits of theoretical understanding is not intended to discredit theoretical knowledge in one or another of its forms and, as is often attempted, to set in its place a more or less idealized practical knowledge; but rather to give it a solid basis by freeing it from the distortions arising from the epistemological and social conditions of its production (p. 27)

Here, the data indicate how the participants saw their own personal changes and how they perceived particular features of the learning environment as being important in those changes. We try to summarise what they spoke about, using the representation in Figure 4. The findings, as summarised by our clustering of the participants' perceptions in Figure 4, highlight that the outcomes and learning processes were valued by the participants in the Clemente program, and could be described by them in ways that articulate with objectified ways of discussing educational processes and outcomes. While it is not intended to suggest that the participants themselves were talking about direct causation, as suggested by the arrows in the figure, one could relate their words to this traditional way of understanding and evaluating learning, using such theoretical concepts as those of input, process and outcomes (e.g. Stufflebeam, 1983).

\section{[FIGURE 4 ABOUT HERE]}

In the participants' words, the program was seen as successful. The words that they used about new engagement, new directions, new responsibilities, new interests, new thinking abilities, [words about new capacities for 'critical analyses'] and new skills all accord with outcomes valued in education. The ways they referred to active and open engagement in the learning processes, the kinds of thinking that they engaged in, and the critical engagement with others' views are all also highly desired in learning experiences. Moreover, the adult learning principles that the participants observed being utilised by the lecturers were also those that are advocated by educators for engagement, participation and individual change. That is, the data are confirmatory of general literature on adult and lifelong learning (e.g. Sutherland \& Crowther, 2006), critical theory (e.g. Habermas, 1978), and empowerment (e.g. Freire, 1995).

It is recognised that there may be rival explanations for the changes that participants reported. We believe that the Clemente program was causal, however, because it has now been operational for 4 years over 3 sites and with 8 graduates from the program now enrolled in other mainstream university and college programs.

However the purpose of the present paper is not to evaluate the program but to identify any evidence in the transcripts for changes in bodily hexis. The data confirm that some participants found that these changes had been incorporated in their bodies; and this change is less seldom referenced so directly in reports of learning outcomes or in learning processes. Some examples were:

The whole attitude in a way that you walk down the street and approach to everything changes when you... Yes back is a bit straighter and people respond differently even when you go in the shop because you deport yourself differently. Because of this it can have a great amount of effect to change the whole kinesics and the whole psychology of the person who has done the Course and people in turn respond to them according to their new pattern.

I notice that when walking to the bus stop I'm walking with more purpose.

it does change the way you present yourself to society, a lot of your pain goes whether it be emotional or physical ... it's about energy and if you think a certain way well you'll walk a certain way down the street. So you're sending out an energy and people see that. Because I'm a visual artist well it's body language. 
The program appeared to breathe new life into the participants. These reported changes are consonant with changes in bodily hexis as described by Mauss (1934) and Bourdieu (1990). They suggest the kinds of embodiment of new dispositions that are referred to by these authors. Given the ways in which these bodily changes were valued by the participants, and their journeys to this point, these changes are here called 'reclaiming body dispositions' and with this, finding ways to start to move beyond the body's continually being captured by the past.

Whether such bodily changes may have been more general amongst the participants than reported is open to question. For instance, it is interesting to note that David, who referred to loss of emotional and physical pain during the learning processes was a visual artist; and Kerry, who spoke most about bodily changes, used metaphors when speaking about his aspirations and changes, and was possibly more in touch with translating non-verbal ways of knowing into metaphors and words:

...it's very difficult of course to predict the future so one possible trajectory is into a tertiary institution. Another might be publication for example; it might be journalism practised on a modest scale at first

It's possibly making me feel a little less alienated. I was feeling exceedingly hostile to society because of the way I've been treated over the years to feeling to that degree alienated it consumes quickly as possible still and some of that is perhaps evaporating a little since the sudden prospect of at least having some stake in society as opposed to being permanently at odds with it.

This may suggest that others may also have experienced bodily changes but may not have discerned or had the words to describe such changes. Further research would be needed to investigate this.

\section{Conclusions}

Although, not the subject of the present paper, the findings summarised in Figure 4 support the use of adult and lifelong learning principles in providing empowering learning experiences. In terms of the objective of the present paper, the research data lend support to the idea that there can be successful interventions into the direct unthinking influence of bodily dispositions,

Importantly, the research raises questions about alternative explanations about the durability of set socialised ways of doing things. For example, cognitive research would posit mental representations as a way of explaining automaticity in familiar situations, using the idea of schema (e.g. for a summary see Stevenson, 1994). However, Bourdieu (1990) explicitly repudiates the idea of 'mental representations' and 'knowledge' as explanations for the workings of the habitus. Hence, further research would also be needed to ascertain the relationships among changes in bodily dispositions and the cognitive idea of schema, which can be traced to Bartlett (1932); the ideas of personal or tacit knowledge (Polanyi, 1958); the idea of accommodation advanced by Piaget (1952); and relationships between habitus and the cognitive concepts of encapsulations of knowledge developed over repeated socialised experiences (e.g. Boshuizen, Schmidt, Custers, \& Van De Wiel, 1995).

One possible implication from the study for vocational education and training is for the focus of such learning. In vocational education the contemporary focus, especially from funding bodies is on predetermined skills and, if learners are fortunate, any underlying 'knowledge'. This focus is often expressed in terms of learning outcomes or competence - performances that the learner can demonstrate, particularly in work settings. Certainly demonstration is bodily. So, it is bodily changes through physical action that are being targeted explicitly by many vocational education and training programs. However, the emphasis is explicitly utilitarian and there is no emphasis on gaining a critical distance from the perpetuating effects of durable dispositions that have been inculcated through repeated socialisation. So the perpetuation of dispositions that may have become inappropriate in terms of the individual's goals is unchallenged. Yet such dispositions may well be one of the reasons why people are unable to secure or keep jobs. Certainly, in vocational education 
and training, there is some scope for developing some conceptual understanding of technical matters, but this is a far cry from engendering an openness to plural views and ways of interpreting the world, and being self-critical on the basis of an analysis of such opinions.

It is not intended to suggest here that all vocational education and training should involve extensive studies of the humanities. Certainly, there needs to be room for the purely technical, especially for re-training and short term needs. However, the equation of technical skill development with the needs of all people entering vocational education may well be too simplistic, if we assume that the changes that occurred with these participants were due to the Clemente program. The wide variety of people entering vocational education and training from different social situations and with different aspirations suggests that more consideration may be needed of the need to gain some critical distance from enduring inculcated personal dispositions which impose limits on career development. Moreover, a rapidly changing world of work almost inevitably requires new kinds of bodily dispositions in dealing with new kinds of materials, processes, systems and information.

In this study, if it was the focus on the humanities that liberated homeless people from the selfperpetuation of their situation, this would support the need for vocational educators to re-appraise the role of general education in helping such vocational education learners, in particular, to develop the attributes needed in working life. Moreover, with the removal of 'life skills', 'general education' and the like in the wake of competency-based training in most Western countries, the divorce between competence and critical engagement with socialised ways of being, seeing and doing seems limiting, especially for disadvantaged learners, in the light of this study. Certainly, it is suggested that there needs to be adequate attention to the individual learner and their dispositions when providing vocational education.

\section{References}

Bartlett, F.C. (1932). Remembering. A study in experimental and social psychology. Cambridge: Cambridge University Press.

Boshuizen, H.P.A., Schmidt, H.G., Custers, E.J. \& Van De Wiel, M.W. (1995). Knowledge development and restructuring in the domain of medicine, the role of theory and practice. Learning and Instruction, 5, 269-285.

Bourdieu, P. (1990). The Logic of Practice. Cambridge: Polity Press. (Translated by Richard Nice)

Bourdieu, P. (1991). Language and Symbolic Power. Cambridge, Mass: Harvard University Press. (Edited and introduced by John B Thompson; Translated by Gino Raymond and Matthew Adamson)

Butcher, J., Howard, P., \& McFadden, M. (2003). Communities and universities: partners for engaged citizenship. International Symposium Universities and Communities: Partners in Building Capacity for Social Justice. Sydney $13^{\text {th }}-15^{\text {th }}$ February, 2003.

Carlton, S., \& Soulsby, J. (1999). Learning to grow older and bolder. Leicester: NIACE.

Chamberlain, C. \& MacKenzie, D. (2001). Counting the homeless. Australian Bureau of Statistics: Canberra.

Cox, R., \& Pascall, G. (1994). Individualism, self-evaluation and self-fulfilment in the experience of mature women students. International Journal of Lifelong Education, 13(2), 159-173.

Emler, N., \& Eraser, E. (1999). Politics, the education effect. Oxford Review of Education, 25(1/2), 251-273.

Friere, P. (1995). Pedagogy of hope : reliving Pedagogy of the oppressed (Ttrans. R. Barr). London: Continuum.

Habermas, J. (1978). Knowledge and human interests. (Trans. J. Shapiro). London : Heinemann Educational

Hammond, C. (2004). Impacts of lifelong learning upon emotional resilience, psychological and mental health: fieldwork evidence. Oxford Review of Education, 30(4), 551-568. 
Havelock, E.A. (1963). Preface to Plato. Cambridge, Mass: Harvard University Press.

MacKnee, C. \& Mervyn, J. (2002). Critical incidents that facilitate homeless people's transition off the streets. Journal of Social Distress and the Homeless, 11 (4), 293-306.

Mauss, Marcel (1934), Techniques of the body. Journal de psychologie normal et patholigique paris, Année XXXII (1935) pp. 271-273. Reprinted in Marcel Mauss (1968). Sociologie et Anthropologie (with introduction by Claude Levi-Strauss), $4^{\text {th }}$ Edition, paris: Presses Universitaires de France, 1968. pp. 364-386.

Piaget, J. (1952). The origins of intelligence in children. New York: International Universities Press.

Polanyi, M. (1969)[1958]. Personal knowledge: towards a post-critical philosophy. Third Impression. London: Routledge \& Kegan Paul.

Qureshi, H. (1992). Integrating methods in applied research in social policy: A case study. In J. Branned (Ed.), Mixing methods: qualitative and quantitative research. Avebury: Aldershot.

Shorris , E. (2000). Riches for the poor:The Clemente Course in the Humanities. New York: W.W. Norton.

Stufflebeam, D. L. (1983). The CIPP model for program evaluation. In G. F. Madaus, M. Scriven, \& D. L. Stufflebeam (Eds.), Evaluation models (Chapter 7, pp. 117-141). Boston: KluwerNijhoff

Sutherland, P \& Crowther, J. (1996). Lifelong learning : concepts and contexts. London: Routledge Wertheimer, A. (1997). Images of possibility. Creating learning opportunities for adults with mental health difficulties. Leicester: National Institute of Adult Continuing Education.

Yashin-Shaw, I, Howard, P, \& Butcher, J. (2005). Educating disaffected adult learners: re-engaging the homeless through tertiary level humanities studies. In J. Searle, F. Beven, \& R. Roebuck. (Eds.), Vocational learning: transitions, partnerships and sustainable futures. Proceedings of the $13^{\text {th }}$ Annual International Conference on Post-Compulsory Education and Training.

Brisbane: Australian Academic Press. 
So I'm climbing back up again and testing how far I can manage to get and this is helping me to satisfy my curiosity on an academic level, my ability to study at a research level, extra curricula outside of the structured course. (Lindsay, 45)

For me to be doing the Course, to be doing the research, to be going to the library, to be reading the books, to be learning the history is the victory. (David, 100)

Well I found the Course very positive because it has certain skills, for example I had no training on the computer and I'm learning to use the computer for the first time in the Course. I was able to develop some academic skills such as essay writing and research and to develop those to almost a professional level. ... The capacity to think as such which is what's being developed in the Course can be applied in numerous directions...Definitely yes it definitely makes a difference. The whole attitude in a way that you walk down the street and approach to everything changes when you... Yes back is a bit straighter and people respond differently even when you go in the shop because you deport yourself differently. Because of this it can have a great amount of effect to change the whole kinesics and the whole psychology of the person who has done the Course and people in turn respond to them according to their new pattern. It really can be as dramatic as all that...(Kerry, 67-142)

... she noticed that I'm very much more organised and dedicated to things and, I don't know she does mention that I'm happier and that things seem to be going well ... I do find that now I'm actually more dedicated than what I was when I was at school because I have a different, I feel responsible in learning well and doing well but also because of my past. But I want to learn as well. (Sarah, 86-92)

Well I feel I've got more purpose now. I notice that when walking to the bus stop I'm walking with more purpose. I've got my notes and things and I carry them around with me I would say 7 days a week because I always think I can read something on the bus. ... but I've got a long way to go before I get myself completely together, but I just know when I get into something subject that I'm really interested in I don't want to stop. ... But I think I've just got to do a little bit more climbing up before I can get back into that with more confidence but this is the way to go. ... I look in the mirror now and instead of sort of thinking 'poor me poor me' ... this has enabled me to put those aside and to do this. ... Do you know I'm beginning to think I haven’t lost it. (Tess,22-80)

I have an interest anyway but now it gives me more background. (Jack, 78)... It made me appreciate Australia more for some of the opportunities. ... It has an after-effect. You know you might go home and you'll see John Howard make a speech, I mention his name you know because it's a free country and you might voice your opinion, well that's what's great about Australia democracy it's called right, you know you might listen to John Howard make a speech and say gee that's a load of baloney, you know because you've had some experience about it and you know it's not so because of things that you've learnt. ... It teaches you that when you read the Financial Review, you read about something like that, not everything is true.

(Jack, 78-200)

Figure 1: Reported Outcomes and Changes (Emphasis added) 
So the ethics course was a lifeline. It gave a purpose to each day as it came along (Betty, 89)

It's exciting because you can see a change in your daily structure. Instead of having you know boredom facing you every day with no goals you have something to strive for and exciting I mean you're learning ... Coming to a conclusion is very rewarding. ... The thought processes, you know as I was saying before it comes down to the very way we think and without even speaking the thought processes you know have profound implications that we don't even realise and as my friend was speaking about how it does change the way you present yourself to society, a lot of your pain goes whether it be emotional or physical ... it's about energy and if you think a certain way well you'll walk a certain way down the street. So you're sending out an energy and people see that. Because I'm a visual artist well it's body language. (David, 75-144)

Yes and just to get involved this aspect combined writing and talking and expressing in the best possible way to get to the point. ... It is the quality of the job that counts right and thinking, what kind of thinking, I mean the quality of thinking; because you can think a lot of useless things you know that. You know whatever and most the people cannot think because it's not easy task. People can grasp somebody else thinking or possibly anything go up to a point but thinking it is just like an art and like a skill inside. Then you have to know how to apply what kind of. (Ron, 65-130)

It's possibly making me feel a little less alienated. I was feeling exceedingly hostile to society because of the way I've been treated over the years to feeling to that degree alienated it consumes quickly as possible still and some of that is perhaps evaporating a little since the sudden prospect of at least having some stake in society as opposed to being permanently at odds with it. (Kerry, 99)

To me history was something that was not reachable, you couldn't touch it, like it was something that was in history books and the teacher knew the information and that was it. They told us the dates of what things happened, but with this class it's a bunch of people and we all discuss how it actually relates to real life ... and every time I find that I come away learning things that I, not even just about history but things about life that I didn't think about. It expands your mind to think broadly in different elements about how to interact with people ... All of a sudden you realise that you've got to be more open to different things. ... it's like a learning experience through writing the essay, it's not just writing an essay on paper or typing it up or whatever, I kind of bring it into everyday life just like I do the class, it kind of balances out my life, but the essay itself like I find that people start talking ... it means that everything else I do I get a lot of things done the rest of the week because I find that my time is more valuable. It just means that I structure my time more and it means that, I have to go to class... it makes me more organised in the rest of my life, ...(Sarah, 36-78)

Well on a personal level here when you're dealing with the other students here you find that everyone has a different point of view and it pays to listen and you actually learn a lot you know. Not only from the Course but actually from being around the other students and listen to their experience in life and background. ... What I find there's always one healthy debate, which I find is good. I mean if we all had the same opinions you know it defeats the purpose. (Jack, 40-70)

Figure 2: Reported Learning Processes (emphasis added) 
He was very informal in how presented each of these issues to us ... He always had a very positive atmosphere. He never looked at any question as being a silly question, even if it may have been a slightly silly question. He answered everything as totally honestly as he can and could without ever giving a biased opinion of his own so that really earned my respect straight away because it is one of the hardest, ... I liked the way he created a discussion amongst the people because straight away once we were involved in discussion we were able to look at each other in a different way. ... But with this type of thing our minds were focused onto what we were actually reading about while we were learning and what was making us think about things. ... the Ethics itself, that Course was informally taught, whereas with Dr XXXX, he tends to be slightly more formal in his approach in that he, what he does is he gives us the whiteboard, he gives us the video, he gives us the handout but he always discusses the handout when he gives it to us, he doesn't just give us 5 or 6 of them and then just leave them with us. (Betty, 97-139)

He is very flexible but he does keep going on the subject; he doesn't just go out and let everyone. ... but he's opening the door to what, he's bringing in information of historical events but he's bringing it in, in a way that we can make it ours, we can bring it into our reality and our way of understanding. And we're talking about what we relate to that, and how we relate to that, and it makes it into a discussion and we learn at the same time as learning about real things that happen. ...the Tutor is as flexible as Peter but he is bringing in the technical element, the elements to get me more disciplined in putting bits and pieces that don't relate to the question. You know how you do when you talk kind of go off in a different direction, but he's just giving me more structure. ... We have a booklet that every week has the particular workshop we have that day and we go through it but I find that I limited in that it's only from that. Even though we do discuss it and Peter brings in what he's written for us I'd like to have outer external information from different sources, from different. I mean access to books. (Sarah, 56-114)

... I got a bit of a surprise that it's actually, it's equivalent to what a first year student does at Catholic University full-on, there's no concessions, you know, you've got to turn up, you've got to do your assignments, ... he actually doesn't teach; he creates a learning environment and makes it interesting, a learning environment on which we teach ourselves you know where our input and there's no smack on the hand if you get the wrong answer, it's not about punishment or anything like that it's about getting your idea across. Well it's about learning. ... no-one feels left out. ... his style is that he makes sure everyone is involved, there's no sleepers in the class. ... Yeah, but actually, he'll confront you on that, he'll say, well, "What is your opinion about that article in the Bulletin?” So he'll actually ask, it's a polite confrontation that he uses ... You've got to have a massive amount of self-discipline. ...doing the Course each week you've actually got a due date for your tutorial, you're actually pushed along in some ways, in so many ways you push along you've got certain obligations to meet here. (Jack, 32148)

\section{Figure 3: Reported Teaching Approaches}




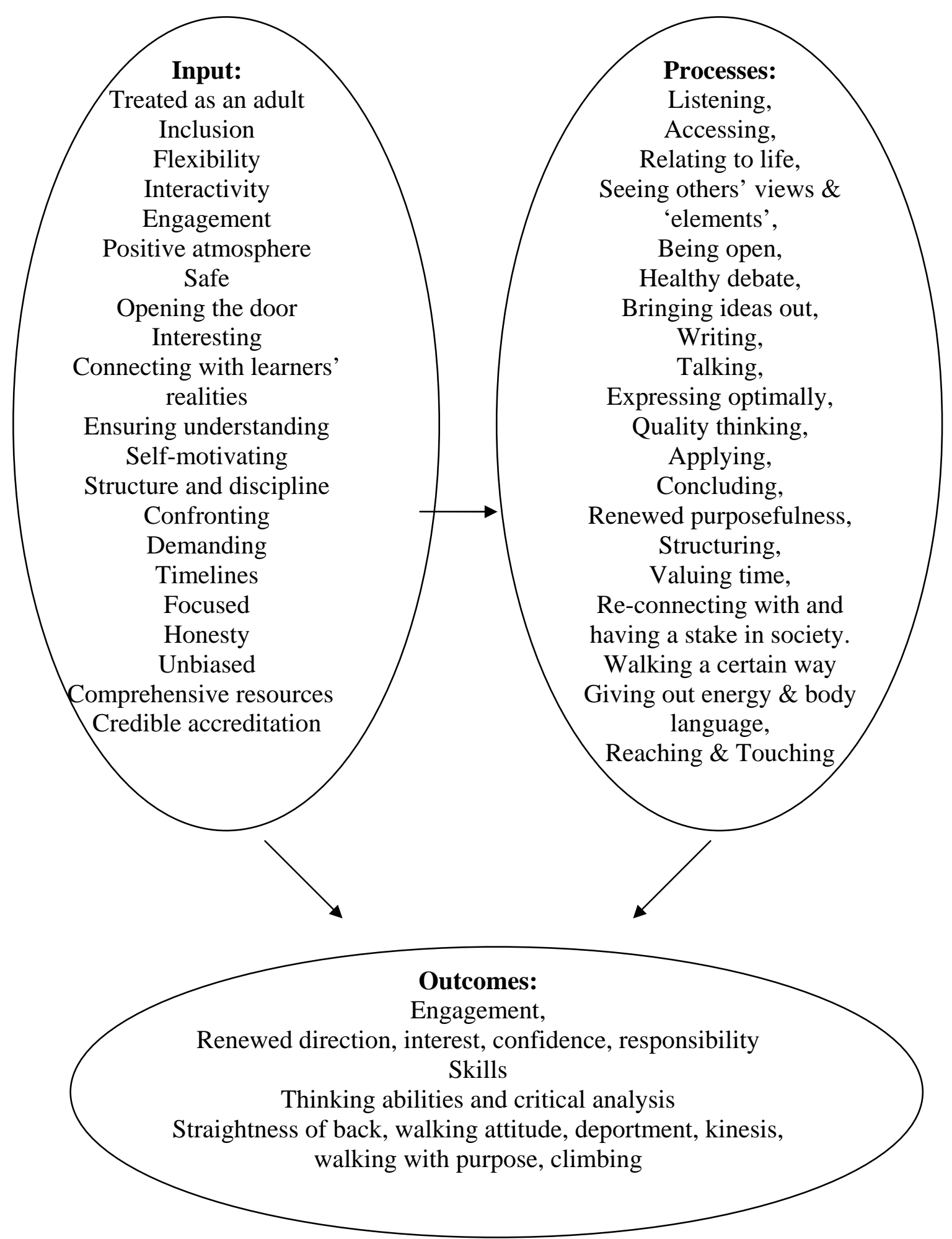

Figure 4: Summary of Participants Reports on Course Inputs, Processes and Outcomes 